2. McLeod SD, Flowers CW, Lopez PF, et al. Endophthalmitis and orbital cellulitis after radial keratotomy. Ophthalmology 1995;102:1902-7.

3. Kimbrough BO, Young AB, Modica LA. Orbital cellulitis and cavernous sinus thrombosis after cataract extraction and lens implantation. Ann Ophthalmol 1992;24:313-7.

4. Hofbauer JD, Gordon LK, Palmer J. Acute orbital cellulitis after peribulbar injection. Am J Ophthalmol 1994;118:391-2.

5. Jackson K, Baker SR. Clinical implications of orbital cellulitis. Laryngoscope 1986;96:568-74.

6. Roman SJ, Chong-Sit DA, Boureau CM, et al. Sub-Tenon's anaesthesia: an efficient and safe technique. Br J Ophthalmol 1997;81:673-6.

7. Rose GE, Howard DJ, Watts MR. Periorbital necrotising fasciitis. Eye 1991;5:736-40.

8. Shayegani A, MacFarlane D, Kazim M, Grossman ME. Streptococcal gangrene of the eyelids and orbit. Am J Ophthalmol 1995;120:784-92.

9. Brun-Buisson CJ, Saada M, Trunet P, et al. Haemolytic streptococcal gangrene and non-steroidal anti-inflammatory drugs. BMJ Clin Res Ed 1985;290:1786.

Brian Redmill

Charles Sandy

Geoffrey E. Rose

Orbital Service

Moorfields Eye Hospital

London EC1V 2PD, UK

Mr B. Redmill

Department of Ophthalmology

Lincoln County Hospital

Greetwell Road

Lincoln LN2 5QY, UK

Tel: +44 (0)1522 573949

e-mail: brianredmill@mac.com

Sir,

\section{Keratoconus associated with a chromosome 7, 11 translocation}

We present a case of keratoconus with a balanced chromosome translocation between chromosomes 7 and 11. The keratoconus is demonstrated with corneal topography. Chromosomal rearrangements should be considered in cases of keratoconus presenting in childhood.

Keratoconus is an ectatic corneal disorder with a prevalence of about 50 in $100000 .{ }^{1}$ The hereditary pattern of keratoconus is not predictable, and family histories have been reported in $6-8 \%$ of cases. In some families, the suggested mode of inheritance is autosomal dominant with variable penetrance and expression. ${ }^{2}$ Keratoconus has been described with a number of systemic conditions, including Marfan's and Ehlers Danlos syndromes. Keratoconus is also recognised to be more frequent in two chromosomal conditions: Down's syndrome (trisomy 21) and Turner's syndrome. ${ }^{2}$ Recently, an association with a chromosome 13 ring abnormality has been described. ${ }^{3}$

\section{Case report}

A 13-year-old girl with short stature was referred from her optician to the eye clinic with myopic astigmatism as she was found to have frequent changes in her refraction. She wore gas-permeable contact lenses.

Snellen visual acuity was $6 / 24$ unaided right (6/9 with contact lens) and counting fingers left (6/9 with contact lens). Refraction was right $+1.50 /-5.00 \times 80$, left $-9.00 /-2.50 \times 80$. Examination of the left cornea showed it to be steep with central apical mid-stromal scars and Vogt's striae. The mid-stromal scars were due to an episode of left acute hydrops which settled on conservative treatment. The right cornea was normal in appearance. Corneal topography of the right eye demonstrated the astigmatism and inferior corneal steepening typical of keratoconus (Fig. 1). ${ }^{4}$ The left corneal topography showed over 17 dioptres of astigmatism and corneal steepening inferiorly.

The patient had been investigated at the age of 12 years for short stature. She was not dysmorphic and systemic examination was unremarkable. As part of the investigative process chromosome analysis was done. A blood sample revealed a balanced translocation between the long arms of chromosome 7 and 11. The karyotype was 46, XX, t(7,11)(q34; q13.3), inv (9)(p11q12).

Chromosome analysis of the mother's blood showed a pericentric inversion of chromosome 7q22.1-q34, which was also present in the mother's sister; neither the mother nor the maternal aunt had keratoconus. The father had normal eyes: his chromosomes showed a pericentric inversion of chromosome 9 .

A radiograph of the proband's wrist showed that bone age was 2-3 years behind actual age. All other investigations, including pelvic ultrasound and hormonal profile (total $\mathrm{T}_{4}$, estradiol, luteinising hormone, follicle stimulating hormone, prolactin and progesterone), were normal. The short stature was attributed to delayed puberty, with menarche commencing at age 15 years, and the patient is now normal height and weight.

\section{Comment}

This girl with delayed puberty and keratoconus had no family history of keratoconus and two normal older female siblings. She has a de novo balanced translocation between the long arms of chromosome 7 and 11 as well as a familial pericentric inversion of chromosome 9. Both parents have pericentric inversions: the father of chromosome 9, as seen in the proband, and the mother of chromosome 7.

Pericentric inversion of chromosome 9 is a normal variant and is not associated with keratoconus. Such inversions are relatively common and are not known to predispose to de novo translocations in offspring. However, since the maternal inversion and translocation in the proband have a common breakpoint on 


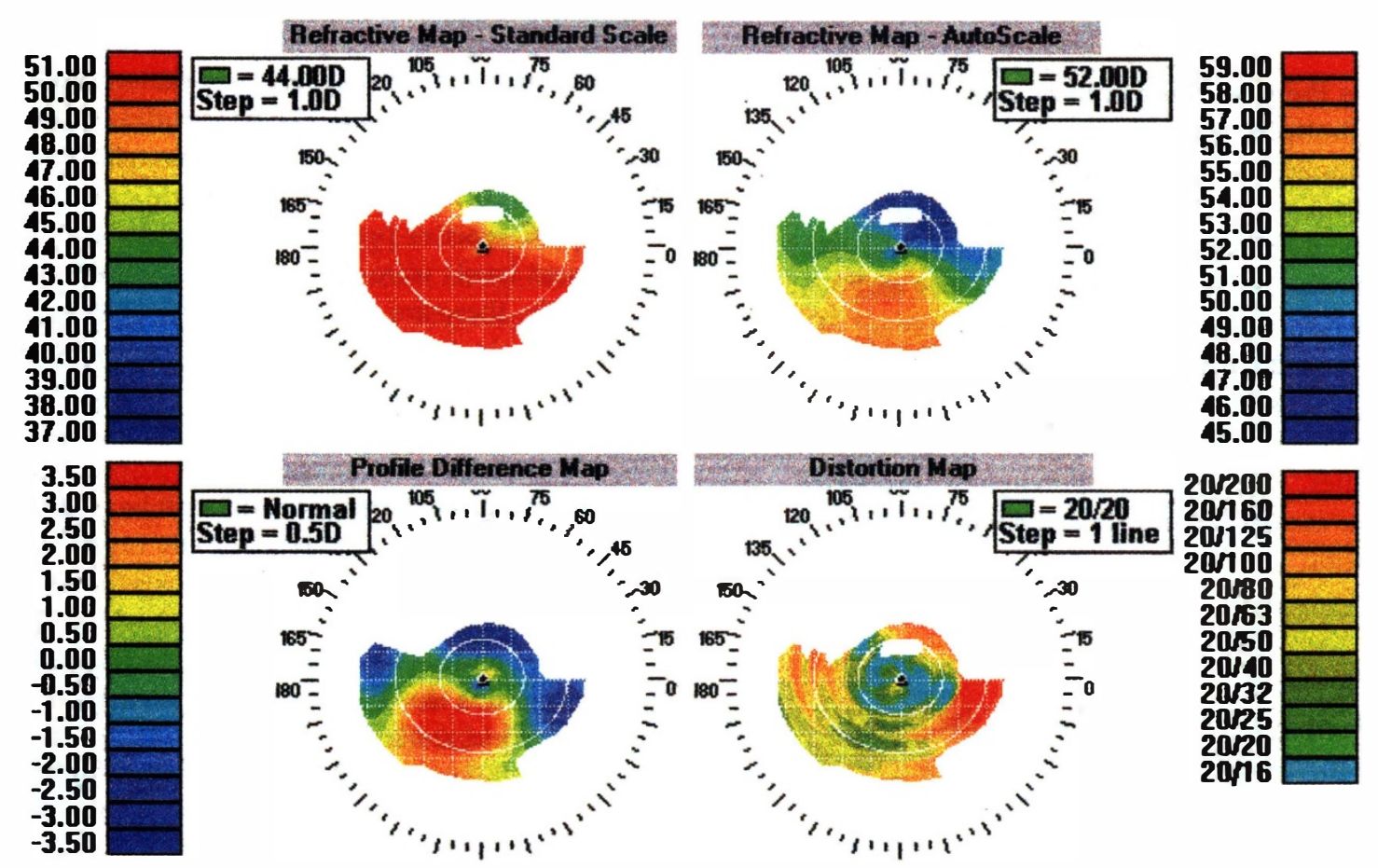

\begin{tabular}{|c|c|c|c|c|c|c|}
\hline $\begin{array}{l}\text { Stoep RP } \\
\text { Ret RP } \\
\text { Tot Astio } \\
\text { ET RP }\end{array}$ & 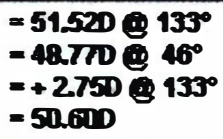 & $\begin{array}{l}\text { Steep Sin K } \\
\text { Pei } \operatorname{Sin} K \\
\text { Deta K } \\
\operatorname{Aog} \operatorname{Sin} K\end{array}$ & $\begin{array}{l}=51920 \div 137^{\circ} \\
=48110 \bigcirc 47^{\circ} \\
=+2820 \bigcirc 137^{\circ} \\
=49410\end{array}$ & 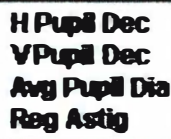 & 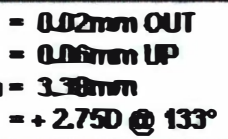 & 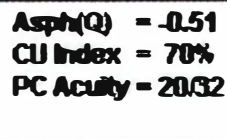 \\
\hline
\end{tabular}

Fig. 1. Corneal topography of the right eye shows the astigmatism and corneal inferior steepening typical of keratoconus.

chromosome 7, it seems likely that in this case the inversion did predispose to the translocation, presumably by the chromosomes becoming tangled in meiosis. That neither the mother nor maternal aunt, both of whom carried the same pericentric inversion of chromosome 7 , was affected suggests that a candidate gene for keratoconus is located at or near the new breakpoint in the proband, i.e. 11q13.3. There are no genes in that region which have been described as causing keratoconus, being involved in collagen production or maintaining corneal integrity.

The pathophysiology of keratoconus is poorly understood, and can represent the ocular manifestation of a connective tissue disease. ${ }^{2}$ Keratoconus is a complex condition of multifactorial aetiology, and there is likely to be genetic heterogeneity. The association of a de novo chromosome abnormality with a particular disease has always been a useful tool in the mapping of genes. It is likely that in this case the association is significant. Chromosome analysis in other cases of keratoconus may detect the chromosome abnormalities which may help localise genes responsible for the condition. ${ }^{5}$ Corneal topography has been used here to confirm the suspected clinical diagnosis.
References

1. Kennedy RH, Bourne WM, Dyer JA. A 48-year clinical and epidemiologic study of keratoconus. Am J Ophthalmol 1986;101:267-73.

2. Ihalainen A. Clinical and epidemiological features of keratoconus: genetic and external factors in the pathogenesis of the disease. Acta Ophthalmol Suppl 1986;178:1-66.

3. Heaven CJ, Lalloo F, McHale E. Keratoconus associated with chromosome 13 ring abnormality. Br J Ophthalmol 2000;84:1079.

4. Rabinowitz YS, Nesburn AB, McDonnell PJ. Videokeratography of the fellow eye in unilateral keratoconus. Ophthalmology 1993;100:181-6.

5. Rabinowitz YS. Keratoconus. Surv Ophthalmol 1998;42:297-319.

Danny A. Morrison ${ }^{1}$

Elisabeth M. Rosser ${ }^{2}$

Charles Claoué ${ }^{1}$

${ }^{1}$ Department of Ophthalmology

Harold Wood Hospital

Romford, UK

${ }^{2}$ Department of Clinical Genetics

Great Ormond Street Hospital

London, UK

Mr Danny A. Morrison, BMedSc, FCRCOphth

Department of Ophthalmology

Harold Wood Hospital

Gubbins Lane

Romford

Essex RM3 OBE, UK 